\title{
Observations of Teleseismic $P$ Wave Coda for Underground Explosions
}

\author{
CHRISTOPHER S. LYNNES ${ }^{1}$ and THORNE LAY ${ }^{1}$
}

\begin{abstract}
The early $P$ wave coda (5-15 sec after the first arrival) of underground explosions at the Nevada Test Site is studied in the time domain using 2082 teleseismic short-period recordings, with the intent of identifying near-source contributions to the signals in the frequency range $0.2-2.0 \mathrm{~Hz}$. Smaller magnitude events tend to have relatively high coda levels in the $0.4-0.8 \mathrm{~Hz}$ frequency band for both Yucca Flat and Pahute Mesa explosions. Coda complexity in this low-frequency passband is negatively correlated with burial depth for Pahute Mesa events but is only weakly correlated with depth for Yucca Flat events. Enhanced excitation of relatively long-period scattered waves for smaller, less deeply buried events is required to explain this behavior. Coda complexity in the $0.8-1.1 \mathrm{~Hz}$ band is positively correlated with magnitude and depth for Pahute Mesa events, but has no such dependence for Yucca Flat events. This may result from systematic variations between the spectra of direct signals and coda arrivals caused by $p P$ interference for the largest events, all of which were detonated at Pahute Mesa. Another possible explanation is a frequency-dependent propagation effect on the direct signals of the larger events, most of which were located in the center of the mesa overlying strong lateral velocity gradients in the crust and upper mantle. Event average complexity varies spatially for both test sites, particularly in the $0.8-1.1 \mathrm{~Hz}$ band, providing evidence for frequency-dependent focussing or scattering by near-source structure. Both the direct arrivals and the early coda have strong azimuthal amplitude patterns that are produced by defocussing by mantle heterogeneity. The direct arrivals have stronger coherent azimuthal patterns than the early coda for Pahute Mesa events, indicating more pronounced deep crustal and shallow mantle defocussing for the direct signals. However, for Yucca Flat events the direct arrivals have less coherent azimuthal patterns than the coda, suggesting that a highly variable component of near-source scattering preferentially affecting the downgoing energy is superimposed on a pattern produced by mantle heterogeneity that affects the entire signal. This complicated behavior of the direct arrivals may be the result of triplications and caustics produced by the complex basement structure known to underlie the Yucca Flat test site. The presence of strong azimuthal patterns in the early coda indicates that source strength estimates based on early coda are subject to biases similar to those affecting estimates based on direct arrivals.
\end{abstract}

Key words: Scattering, coda, underground explosions, yield estimation, wave propagation.

\section{Introduction}

Reliable determination of the energy released by seismic sources is a fundamental problem in earthquake and explosion seismology. For relatively small energy sources, it is necessary to utilize short-period seismic waves to determine the source strengths,

${ }^{1}$ Department of Geological Sciences, University of Michigan, Ann Arbor, MI 48109, U.S.A. 
although it is well-known that the scale lengths of heterogeneity within the earth are such that propagational effects are particularly pronounced for the short-period waves of interest. Thus, there has been a concentrated effort to achieve a better theoretical and empirical understanding of short-period wave propagation processes in the earth. The primary objective in the field of explosion seismology is to develop a procedure for seismic yield estimation using short-period waves that is both precise (i.e., consistent) and accurate.

The currently preferred methods of yield estimation employ seismic magnitude measurements, which can be divided into two classes: those that rely on a direct phase, such as $m_{b}^{a b}$, (based on the first cycle of the short-period $P$ waveform); and those that are based on a scattered phase, such as $L g$ or $P$ coda. The advantage of direct phases is that they can be treated to a large degree as deterministic signals, which are generally expected to be rather simple for underground explosions. This allows quantitative application of corrections for predictable biases arising from source function scaling, free-surface interaction, attenuation variations and propagation effects due to known large-scale three-dimensional structure (LAY et al., 1984; LAY, 1985; CORMIER, 1987). However, the earth is heterogeneous to such a degree that there appears to be a limit to the precision that can be obtained in yield estimation using direct phases (BACHE, 1982). On the other hand, scattered phases must usually be treated stochastically, but they do have the attribute that the scattered arrivals sample many raypaths, presumably averaging out to a large extent the various heterogeneities sampled (AKI, 1982; CORMIER, 1987). Several authors have examined the relative performance of magnitudes based on teleseismic $P$ coda and direct $P$ as relative size estimators, concluding that $P$ coda generally yields more precise size estimates (BullitT and CoRMIER, 1984; BAUMGARDT, 1985; Gupta et al., 1985; LAY and WELC, 1987).

In addition, approximately half of the energy in teleseismic $P$ coda from shallow sources appears to result from near-source scattering (DAINTY, 1985). Thus, the $P$ coda may provide information about the source region, either through use as a reference for examining direct signal behavior (GUPTA and BLANDFORD, 1987), or by analysis of the coda itself (LAY and WELC, 1987; LAY, 1987a,b). While some empirical progress has been made in using $P$ coda for both size estimates and determining source properties, the exact origins of $P$ coda remain somewhat enigmatic. It presumably is generated by scattering from small-scale heterogeneities and may therefore be useful for characterizing crust and mantle velocity variations. However, the relative importance of processes such as mode conversions, forward scattering or back scattering is not well established. Improving our knowledge of the processes involved in the generation of $P$ coda is essential to a basic understanding of shortperiod wave propagation in the earth.

In this paper, we will examine the properties of the early $P$ coda (defined here as the first 5-15 sec after the first arrival of the $P$ wave) from underground explosions at the Nevada Test Site. The early coda is particularly interesting since there is some 
possibility of treating it deterministically as well as statistically, because the nearsource contributions must be generated within a restricted volume around the source. Deterministic treatments that attempt to explain particular arrivals in the coda are presented by BOUCHER (1973), who analyzed the first $3 \mathrm{sec}$ of near-source recordings, and by LAY (1987b) who inverted for isotropic scatterers using the first $15 \mathrm{sec}$ of the $P$ wavetrain. However, inversions of the latter type are still very difficult and poorly posed due to our lack of knowledge of the predominant scattering mechanisms producing the coda; accordingly, in this study, we will examine the statistical properties of the early $P$ coda empirically, to motivate and help design future inversions for scatterers. These properties will also provide an observational basis for evaluating the size estimation capabilities of the early coda.

The statistical properties of early $P$ coda have already been extensively studied for explosions at the Pahute Mesa test site, as well as for the two Novaya Zemlya test sites and the Amchitka test site by LAY and WELC (1987) and LAY (1987a). One of the interesting results obtained in these data-intensive studies was the detection of a negative correlation of coda "complexity" (power in the coda relative to the direct arrival) with both magnitude and depth of burial in the $0.40 .8 \mathrm{~Hz}$ frequency band for all sites studied. Similar correlations were noted for Novaya Zemlya and Amchitka for the $0.8-1.1 \mathrm{~Hz}, 1.1-1.5 \mathrm{~Hz}$ and $0.2-2.0 \mathrm{~Hz}$ bands, while Pahute Mesa explosions exhibit a positive correlation of complexity with magnitude/depth in the $0.8-1.1 \mathrm{~Hz}$ band. Spatial correlations of coda complexity were also noted for the Pahute Mesa test site, with complexity increasing toward the center of the test site. No correlation with tectonic release $F$-factor was found; thus, it appears that aftershocks do not contribute significant high frequency energy to the coda, as had been suggested by Douglas (1984) on the basis of analysis of the Pahute Mesa explosion GREELEY.

Another interesting result from the study of Pahute Mesa coda was the detection of systematic azimuthal patterns in the early coda amplitudes that mirror the patterns in the direct arrivals, albeit with a somewhat smaller range of variation. In a detailed analysis of the direct signals, LYNNES and LAY (1988) demonstrated a correlation between low $m_{b}^{a b}$ and fast travel times for Pahute Mesa explosions, which they attributed to strong focussing/defocussing effects in the lithosphere and in the deep mantle. Thus, it appears that the near-source component of the early coda is affected by the same deep mantle heterogeneity, rather than having effectively averaged out all of the propagational effects. Similar correlations between coda and direct arrival amplitudes have been observed by BULLITT and CORMIER (1984) and BAUMGARDT (1985).

In this study, we have digitized 1063 WWSSN and Canadian Seismic Network seismograms from 32 Yucca Flat explosions to complement the 1019 seismograms from 25 Pahute Mesa tests analyzed by LAY and WELC (1987) and LAY (1987a,b). As in these earlier studies, we identify the near-source contribution to the early $P$ coda by using a large, well-distributed station set. The dependence of coda 
complexity on various event parameters such as depth and magnitude is determined for the two test sites. We also examine the individual event average complexity values in order to look for coherent spatial variations within the test sites. Such variations provide prime motivations for future attempts to identify particular scattering structures. Finally, the azimuthal patterns of the direct arrivals and coda for the two nearby test sites will be compared to determine the relative importance of near-source and deep mantle effects.

\section{Data Analysis}

The seismograms for Yucca Flat events were processed in a nearly identical manner to those for Pahute Mesa events, as described in LAY and WELC (1987) and LAY (1987a). At least $15 \mathrm{sec}$ of noise and $15 \mathrm{sec}$ of signal were digitized and interpolated at a $0.1 \mathrm{sec}$ sample interval. The seismograms were filtered using three-pole Butterworth bandpass filters with four different passbands: $0.2-2.0 \mathrm{~Hz}$ ("broadband"), $0.4-0.8 \mathrm{~Hz}$ (low-frequency), $0.8-1.1 \mathrm{~Hz}$ (mid-frequency), and $1.1-1.5 \mathrm{~Hz}$ (high-frequency). The individual instrument responses were deconvolved from the low-frequency, mid-frequency and high-frequency data sets before filtering; however, deconvolutions of the "broadband" seismograms were unstable at the long period end, so the instrument response was not removed from this data set. Since most of the stations are from the WWSSN, this results only in a slight increase of the variance in the broadband results.

In order to characterize the complexity of the coda, the normalized energy temporal centroid (MCLAUGHLIN and ANDERSON, 1985) of the first $15 \mathrm{sec}$ of the squared analytic envelope (Figure 1) was computed. The energy temporal centroid $\left(C_{b p}\right)$ is defined for each bandpass filtered (bp) seismogram by:

$$
C_{b p}=\int_{0}^{15} s^{2}(t) t d t / \int_{0}^{15} s^{2}(t) d t
$$

where $s^{2}(t)$ is the square of the filtered signal envelope. Larger centroid values indicate a higher proportion of energy later in the signal. A correction for noise level was applied by subtracting the root-mean-square (RMS) of the noise window from the envelope before computing $C_{b p}$; this generally reduced all the event average centroids by comparable amounts. Station/path corrections were determined by averaging the centroids for all events from a given test site recorded at a given station. When computing an event average value of $C_{b p}$, the station corrections were applied, and the corrected centroids were azimuthally averaged in $7.5^{\circ}$ windows to reduce bias from uneven azimuthal distribution. The event centroids for each test site were then demeaned, so that the values reported below are deviations from the average.

The RMS of the direct arrival $(0-5 \mathrm{sec})$ and the coda $(5-15 \mathrm{sec})$ were also computed for each seismogram. The logarithm of the ratio $\mathrm{RMS}^{5-15} / \mathrm{RMS}^{0-5}$ provides 


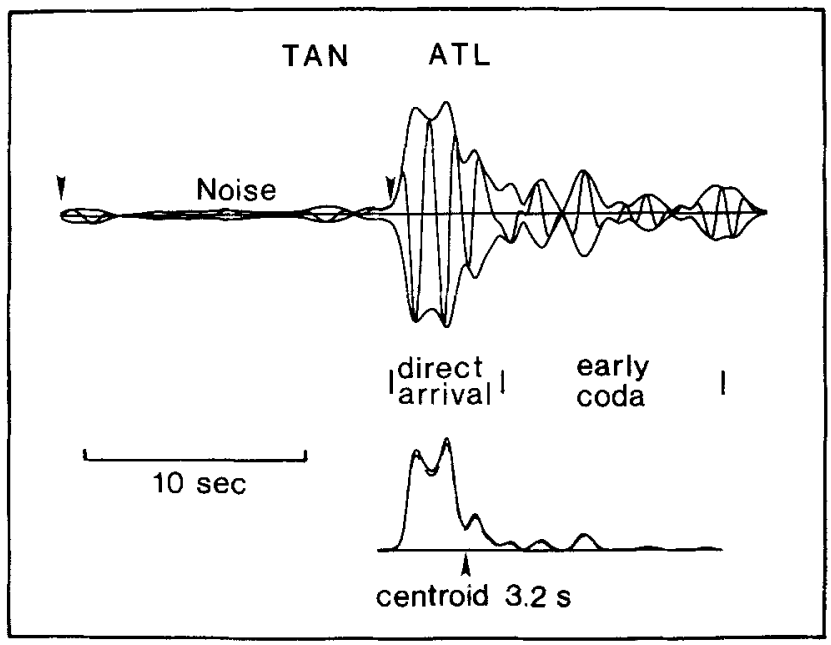

Figure 1

Example of the data analysis procedure. The top trace is the $P$ wavetrain with its analytic envelope, filtered from $0.2-2.0 \mathrm{~Hz}$ for the Yucca Flat event TAN at station ATL. RMS amplitudes are calculated for the first $5 \sec$ (direct arrival) and the 5-15 sec window (early coda). The bottom trace shows the squared envelope, before the noise correction (solid line) and after the noise correction (dashed line), and the effect of the noise correction on the energy temporal centroid.

another measure of the complexity of the coda, with higher values indicating relatively enhanced coda levels. Event averages for $\log \left(\mathbf{R M S}^{5-15} / \mathbf{R M S}^{0-5}\right)$ were calculated in the same manner as for the centroids. The $\log \left(\mathrm{RMS}^{5-15} / \mathrm{RMS}^{0-5}\right)$ measure was used to compare with the behavior of the direct arrival $\left(\log \left(\mathrm{RMS}^{0-5}\right)\right)$ and early coda $\left(\log \left(\mathrm{RMS}^{5-15}\right)\right)$; however the centroids will be preferred in this study when considering event average complexity, since it proved difficult to apply a stable noise correction to the $\log \left(\mathrm{RMS}^{5-15} / \mathrm{RMS}^{0-5}\right)$ measurements. The correlation coefficients, $r$, of the event average centroids (without noise correction) vs. $\log \left(\mathrm{RMS}^{5-15} / \mathrm{RMS}^{0-5}\right.$ ) are $r=0.94$ in the low-frequency band, $r=0.84$ in the mid-frequency band, and $r=0.94$ in the high-frequency band for Yucca Flat events. The broadband correlation coefficient is only $r=0.72$, which may be due to the fact that the seismograms were not deconvolved in this case. In general, however, these two quite different types of coda complexity measures gave very similar results, as was the case for the Pahute Mesa date (LAY and WELC, 1987; LAY, 1987a).

\section{Event Average Complexity}

Correlation with $m b$ and depth. The event average centroids in each frequency band for Yucca Flat were correlated with magnitude, burial depth and depth below the water table. However, the only parameter that gave a correlation coefficient above 0.5 in any of the frequency bands was magnitude. The correlations of coda 
complexity with magnitude and with burial depth in each frequency band for both Yucca Flat and Pahute Mesa events are listed in Table 1. Variance-weighted linear regressions of coda complexity vs. magnitude and depth for both test sites are shown in Figure 2 for the low-frequency and mid-frequency bands.

Both test sites have little magnitude dependence in the broadband and highfrequency band cases. In the mid-frequency band, however, the Pahute Mesa events show a positive correlation of complexity with magnitude $(r=0.62)$ and depth $(r=0.71)$. There is no correlation with magnitude for Yucca Flat, but a similar trend with burial depth, although several outliers lead to a poor correlation coefficient $(r=0.27)$. These correlations may result from variation of the spectrum of the direct arrival in this band due to $p P$ interference. For larger, more deeply buried events, the increase in $p P$ delay time would shift the spectral scalloping from $p P$ interference toward the middle of the passband. This effect can be predicted by computing synthetic spectra for a large, deep event and a small, shallow event. Two Pahute Mesa explosions were used for these computations (Figure 3), because the teleseismic $P$ waveforms for tests at this site have been extensively studied (LAY, 1985). The spectrum of the coda should not have such pronounced scalloping due to $p P$ (GUPTA and BLANDFORD, 1987) and thus the coda amplitudes in this passband would appear relatively enriched.

In order to demonstrate this with actual data, we compared the spectral amplitudes of a $15 \mathrm{~s}$ noise window to two $15 \mathrm{~s}$ windows in the $P$ wavetrain, one including the direct arrival ( $0-12.8 \mathrm{~s})$ and one without the direct arrival $(5-17.8 \mathrm{~s})$. This method of presentation (Figure 4) mitigates the possible effects of noise bias between a large and small explosion. COMMODORE is a large, deeply buried Yucca Flat test, while PIRANHA is a relatively small, shallow event, with an average centroid that is $0.7 \mathrm{~s}$ less than that of COMMODORE in the mid-frequency band. The spectral null related to $p P$ interference is clearly visible in the $0-12.8 \mathrm{~s}$ window, which is dominated by the direct phase, for both events. As in the synthetic case (Figure 3) the null is shifted into the mid-frequency band for the deeper test. This depletes the direct arrival relative to the coda, in which the spectral null is much subdued as seen in the pure coda spectra (5.0-17.8 s). Nevertheless, the null does exert a small effect on the spectral amplitudes, suggesting that the coda has some component of $P$-P scattering.

Table 1

Correlation coefficients of $C_{b p}$ with magnitude and depth of burial

\begin{tabular}{lccccc}
\hline \multicolumn{1}{c}{ Test Site } & Parameter & $0.4-0.8 \mathrm{~Hz}$ & $0.8-1.1 \mathrm{~Hz}$ & $1.1-1.5 \mathrm{~Hz}$ & $0.2-2.0 \mathrm{~Hz}$ \\
\hline Yucca Flat & $m_{b}^{a b}$ & -0.61 & 0.06 & -0.19 & -0.35 \\
Pahute Mesa & $m_{b}^{a b}$ & -0.94 & 0.62 & -0.27 & -0.34 \\
Yucca Flat & depth & -0.33 & 0.27 & -0.09 & -0.06 \\
Pahute Mesa & depth & -0.80 & 0.71 & -0.38 & -0.00 \\
\hline
\end{tabular}




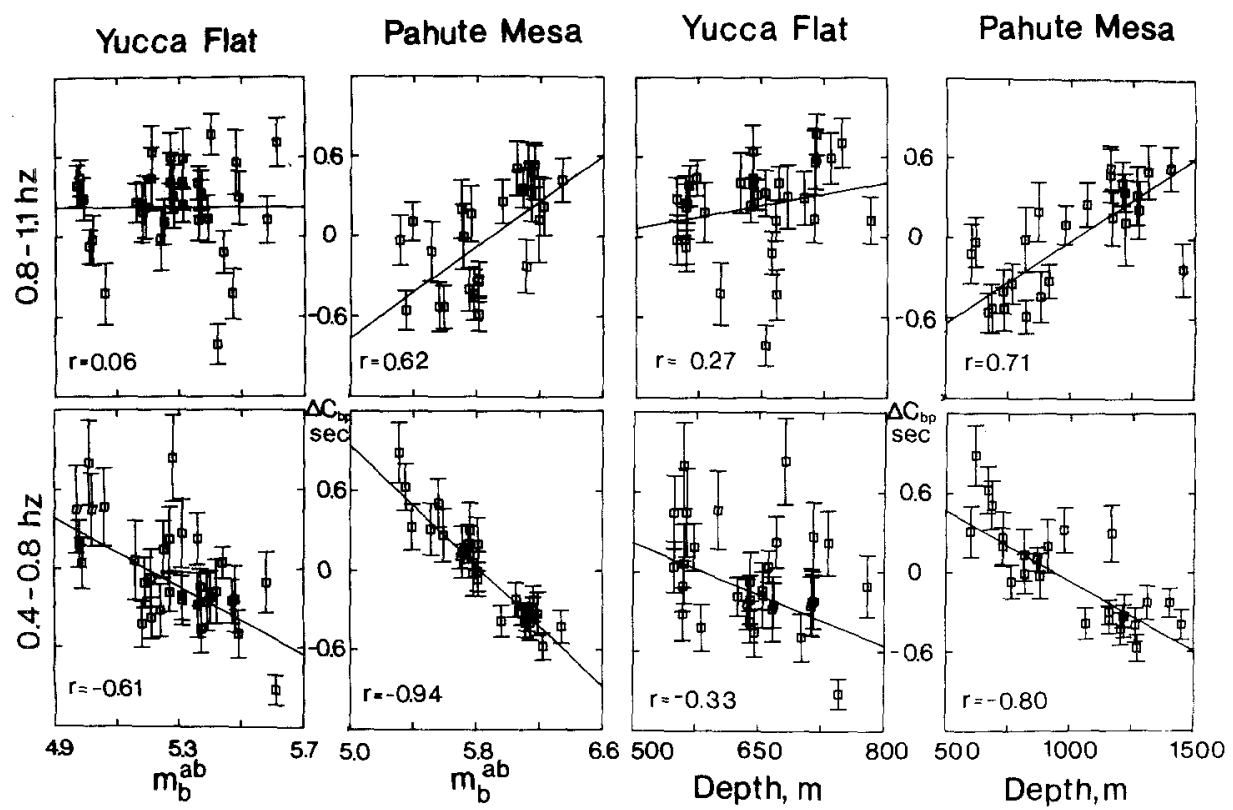

Figure 2

Correlations of relative event average centroids $\left(\Delta C_{b p}\right)$ with magnitude and burial depth in the lowfrequency and mid-frequency bands for Yucca Flat events and Pahute Mesa events.

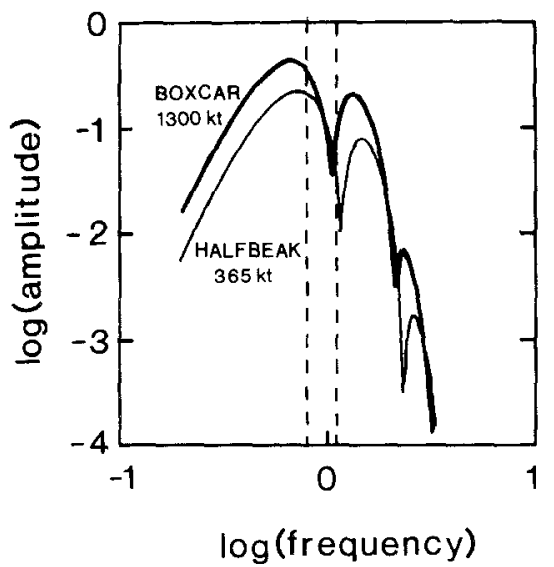

Figure 3

Synthetic amplitude spectra, calculated using $t^{*}=0.75 \mathrm{sec}$ and a short-period WWSSN instrument for a large, deeply buried event (BOXCAR: yield $=1300 \mathrm{kt}$, depth $=1.158 \mathrm{~km}$ ) and a smaller, less deeply buried event (HALFBEAK: yield $=365 \mathrm{kt}$, depth $=0.819 \mathrm{~km}$ ) at Pahute Mesa. The increase in $p P$ delay time for the large event shifts the scalloping effect of $p P$ interference into the mid-frequency band. 

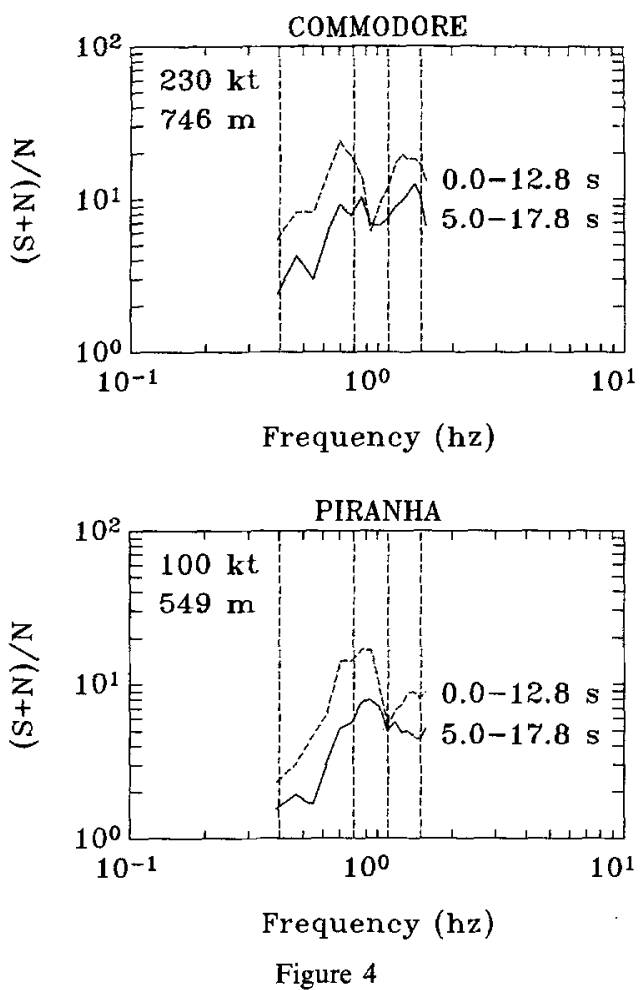

Ratio of seismogram spectral amplitude to noise for a large, deep event (COMMODORE) and a small, shallow event (PIRANHA) at Yucca Flat. The dashed line indicates the 0-12.8 s window, which is dominated by the direct phase, and the 5-17.8 s window, which does not include the direct phase.

Another possibility is frequency dependent defocussing of the direct arrival for events in the center of the mesa, where most of the larger events were located. This second possibility will be tested later by comparing spatial variations of complexity and azimuthal patterns in the different frequency bands.

In the low-frequency band, both test sites show a negative correlation with magnitude ( $r=-0.94$ for Pahute Mesa and $r=-0.61$ for Yucca Flat), with smaller magnitude events having relatively high coda levels. For Pahute Mesa, the lowfrequency band has a similar dependence on depth of burial $(r=-0.80)$. For Yucca Flat events, the dependence of complexity on depth is fairly weak $(r=-0.33)$, suggesting that the correlation of complexity with magnitude cannot be ascribed to depth of burial effects alone, but it is important to note that the Pahute Mesa events span a much greater range in burial depth.

One possibility for these correlations is the effect of $p P$ interference. However, the parallel spectral curves in the $0.4-0.8 \mathrm{~Hz}$ band for both explosions in Figure 4 indicate that this band is relatively free of such interference. Furthermore, the effect of interference should be to decrease the direct arrivals of the larger explosions, as in the mid-frequency band, which would result in a trend opposite of that which is observed. 
Another possibility is that the negative correlation of complexity with size is due to greater noise contamination in this band for smaller explosions. The signal/noise ratio is indeed smaller for PIRANHA than for COMMODORE (Figure 4), but it is still on average fairly high within this band for both tests, dipping below 2 only for the coda of PIRANHA. The effect of noise is further reduced by application of the noise correction to the centroids. Also, although noise will in general increase the centroids, noise that is in phase with the direct arrival decreases the centroids, further mitigating the overall effects of noise. These effects are also reduced by the inclusion of low-noise stations, for which the effects of noise are negligible. Thus, it seems unlikely that noise contamination alone could account for the substantial variation in centroid with magnitude in the low-frequency band.

Spatial variations of complexity. The spatial variation of event average complexity in all four passbands for Yucca Flat is shown in Figure 5. The coherent variations in

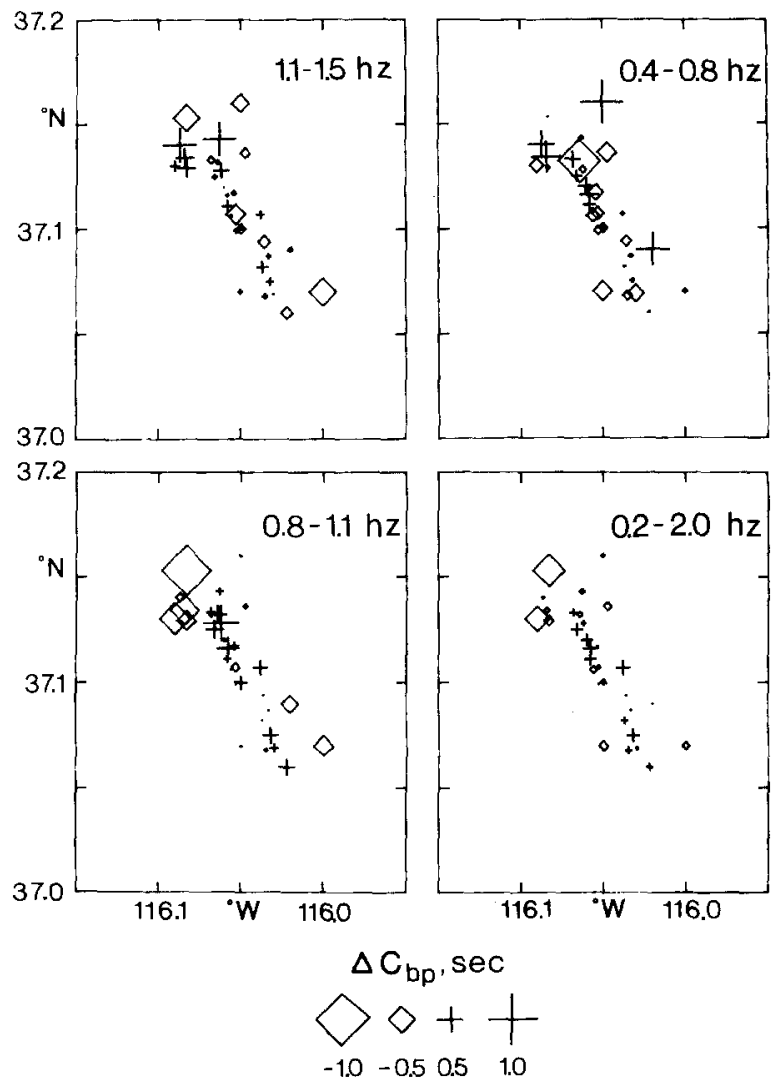

Figure 5

Spatial variation of event average complexity $\left(\Delta C_{b p}\right)$ for the Yucca Flat test site in the four frequency bands. Diamonds indicate smaller than average coda complexity, and crosses larger than average coda complexity. 
complexity with location are quite striking. The least coherent variations occur in the low-frequency band; thus, the complexity in this band appears to be influenced more by magnitude than by the source environment. The most coherent variations occur in the mid-frequency band. This result is consistent with the frequency dependence of spatial variations for Pahute Mesa, where the mid-frequency band had the highest correlation with distance from the center of the mesa ( $r=-0.72$ vs. $r=0.24$ for the low-frequency band and $r=-0.16$ for the high-frequency band). The actual spatial patterns are also somewhat different among the different frequency bands: events in the northwest part of the test array have very low complexity in the mid-frequency band, but relatively high complexity in the high-frequency band; events in the northcentral part, on the other hand, have high complexity in the mid-frequency band, but average complexity in the high-frequency band. The broadband map resembles a subdued version of the mid-frequency band map, due to the predominance of midfrequency band energy in the undeconvolved broadband signals and the compensating trends in the different frequency bands. The difference in patterns among frequency bands suggests a frequency dependence in focussing of the direct arrival or in scattering contributions to the coda.

The spatial variations of coda complexity imply a correlation with some property of the source region. Ferguson's (1982) model for Yucca Flat basin, based on

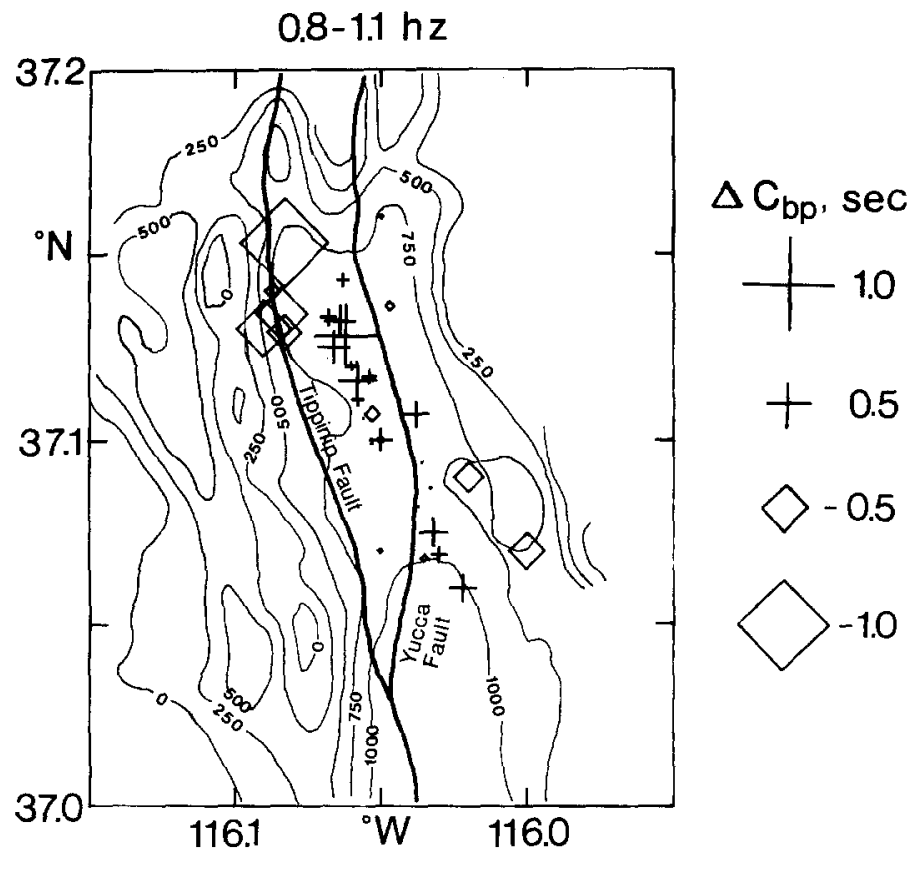

Figure 6

Depth in meters to Tertiary-Paleozoic contact (from FERGUSON, 1982), with event average complexity for the mid-frequency band. 
borehole data and gravity modeling, is shown in Figure 6 with the event average complexity values for the mid-frequency band superimposed. The contours indicate the depth to the Tertiary-Paleozoic contact. The events with the highest complexity lie above the basin axis at the north end, just to the west of the Yucca Fault. The events with the simplest coda levels are situated above the east flank of a horst in the basement. This suggests that either the basin shape or the thickness of Tertiary tuffs controls coda complexity in this passband.

\section{Azimuthal Patterns of Amplitudes and Complexity}

Slowly varying azimuthal patterns of $m_{b}^{a b}$ and travel time residuals have been observed for events at both the Pahute Mesa and Yucca Flat test sites (LYNNES and LAY, 1988). Correlations between the travel time and amplitude variations indicate that a significant component is due to focussing and defocussing by velocity heterogeneities in the mantle. MINSTER et al. (1981) and TAYLOR (1983) found localized high velocity regions in the upper mantle to the northeast of Pahute Mesa, which can produce defocussing that accounts for much of the difference between the Pahute Mesa and Yucca Flat amplitude patterns (LYNNES and LAY, 1988; CORMIER, 1987). However, the patterns for the two test sites share a large common component, which LYNNES and LAY (1988) inferred to be due to defocussing and focussing by deep $(>200 \mathrm{~km}$ ) heterogeneity. It is thus of interest to determine the relative influence of such heterogeneities on the direct arrival and the early coda.

In order to determine the average azimuthal patterns for the direct arrivals $\left(\log \left(\mathrm{RMS}^{0-5}\right)\right)$, early coda $\left(\log \left(\mathrm{RMS}^{5-15}\right)\right)$ and complexity $\left(\log \left(\mathrm{RMS}^{5-15} / \mathrm{RMS}^{0-5}\right)\right)$, the station averages for each site were calculated using a least-squares technique that inverts for the best relative source sizes to simultaneously minimize the variance about the station means (Larry Ruff, personal communication). In order to bring out the slowly varying component of the azimuthal patterns, curves of the form $A \cdot \sin \left[2\left(\theta-\theta_{0}\right)\right]$ were regressed through the resultant station averages as a function of azimuth $(\theta)$. The particular form of the regression curve is not physically motivated, but is intended to parameterize the long-wavelength variations to facilitate comparisons between events and test sites. The $F$-ratio is also calculated as described in LAY et al. (1984) to provide an indicator of the coherence and significance of the long-wavelength component. The results for the broadband set are shown for Pahute Mesa and Yucca Flat in Figure 7.

The direct arrivals $\left(\log \left(\mathrm{RMS}^{0-5}\right)\right)$ show azimuthal patterns for both Pahute Mesa and Yucca Flat, with a somewhat stronger and more coherent pattern for Pahute Mesa. The correlation in the $\log \left(\mathrm{RMS}^{0-5}\right)$ station averages between the test sites is $r=0.83$, while it is $r=0.73$ for the $\log \left(\mathrm{RMS}^{5-15}\right)$ values. Thus, a significant component of the variation is common to the two test sites. LYNNES and LAY (1988) obtained a similar result for $m_{b}^{a b}$ and interpreted the higher amplitude of variation for Pahute Mesa as a result of focussing and defocussing by lateral velocity gradients in 

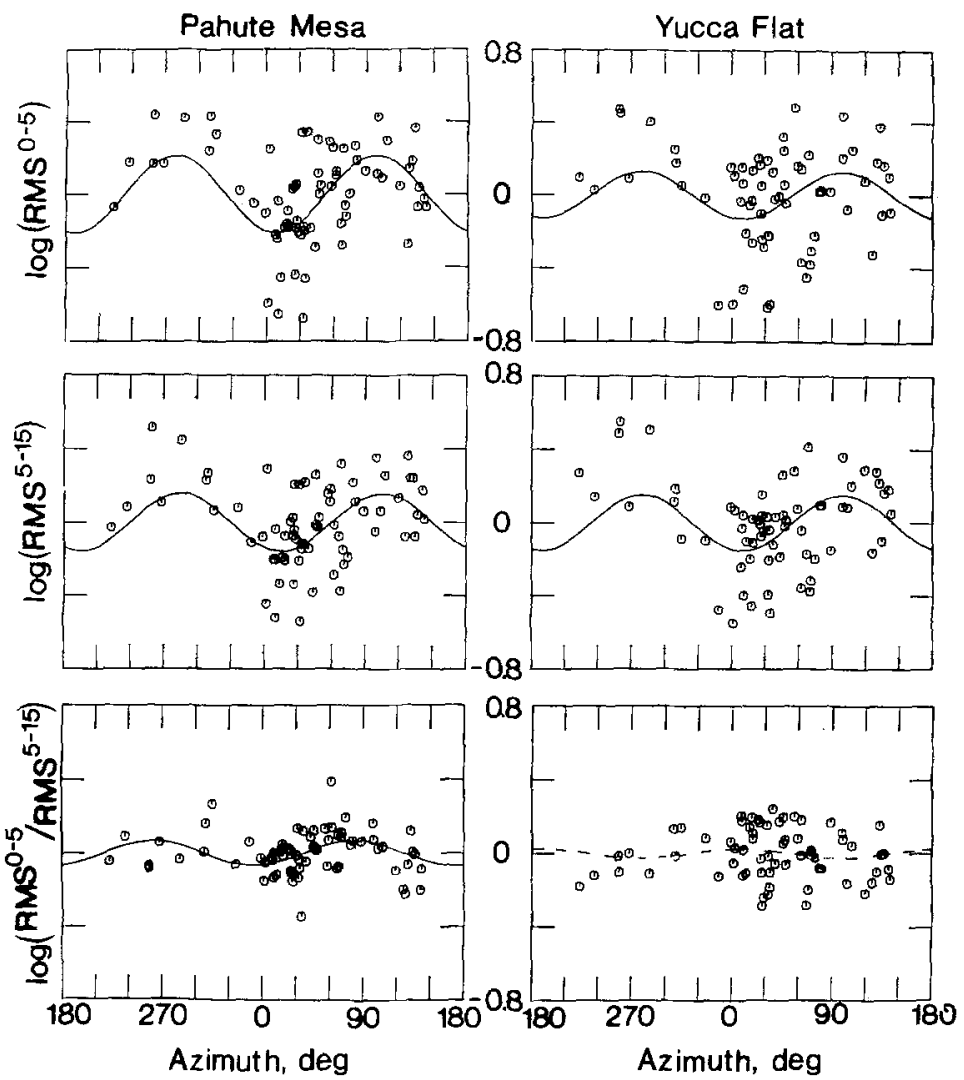

Figure 7

Sin $2 \theta$ regressions for Yucca Flat and Pahute Mesa station averaged $\log \left(\mathrm{RMS}^{0-5}\right), \log \left(\mathrm{RMS}^{\mathrm{S}-15}\right)$ and

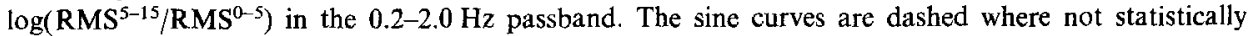
significant at the $95 \%$ level.

the crust and shallow mantle under the mesa. The $\log \left(\mathrm{RMS}^{0-5}\right)$ pattern for Pahute Mesa is stronger than the $\log \left(\mathrm{RMS}^{5-15}\right)$ pattern for the same site, indicating that the focussing/defocussing in the Pahute Mesa direct signals is less pronounced for the early coda due to the averaging characteristics of the scattered wavefield. The $\log \left(\mathrm{RMS}^{5-15}\right)$ pattern for Yucca Flat, however, has a stronger long-wavelength component $(F$-ratio $=7.6)$ with a slightly larger range than the pattern for the direct arrivals $(F$-ratio $=3.9)$ from that site, although the orientation of the patterns are quite similar. This behavior is present in many sine curve regressions of $\log \left(\mathrm{RMS}^{0-5}\right)$ and $\log \left(\right.$ RMS $\left.^{5-15}\right)$ of the individual events as well. Thus, it seems that both the direct arrivals and the coda are affected, more or less equally, by deep mantle heterogeneity, while the decreased significance of the direct arrival sine curves appears to be due to increased scatter in the associated station averages. This might result from very-near-source or near-receiver heterogeneity. The Yucca Flat events were detonated close to large basement offsets on the Yucca Fault (Figure 6), which may cause triplications and 
caustics affecting the direct arrivals and early coda (STEAD and HelmBERGER, 1986). In any case, the homogenization of the early coda seems to have little effect on subduing the predominant amplitude variations induced by earth structure at both sites.

Sine curves were also regressed through the inverse complexity measure $\log \left(\mathrm{RMS}^{0-5} / \mathrm{RMS}^{5-15}\right)$ for Pahute Mesa and Yucca Flat (Figure 7). As might be expected, the Pahute Mesa sine curve is significant $(F$-ratio $=5.2)$, due to the larger range of variations for $\log \left(\mathrm{RMS}^{0-5}\right)$ than for $\left(\mathrm{RMS}^{5-15}\right)$. The Yucca Flat pattern, on the other hand, does not have any long-wavelength variation, indicating that the direct arrival and the phases making up the coda are affected similarly by deep mantle structure.

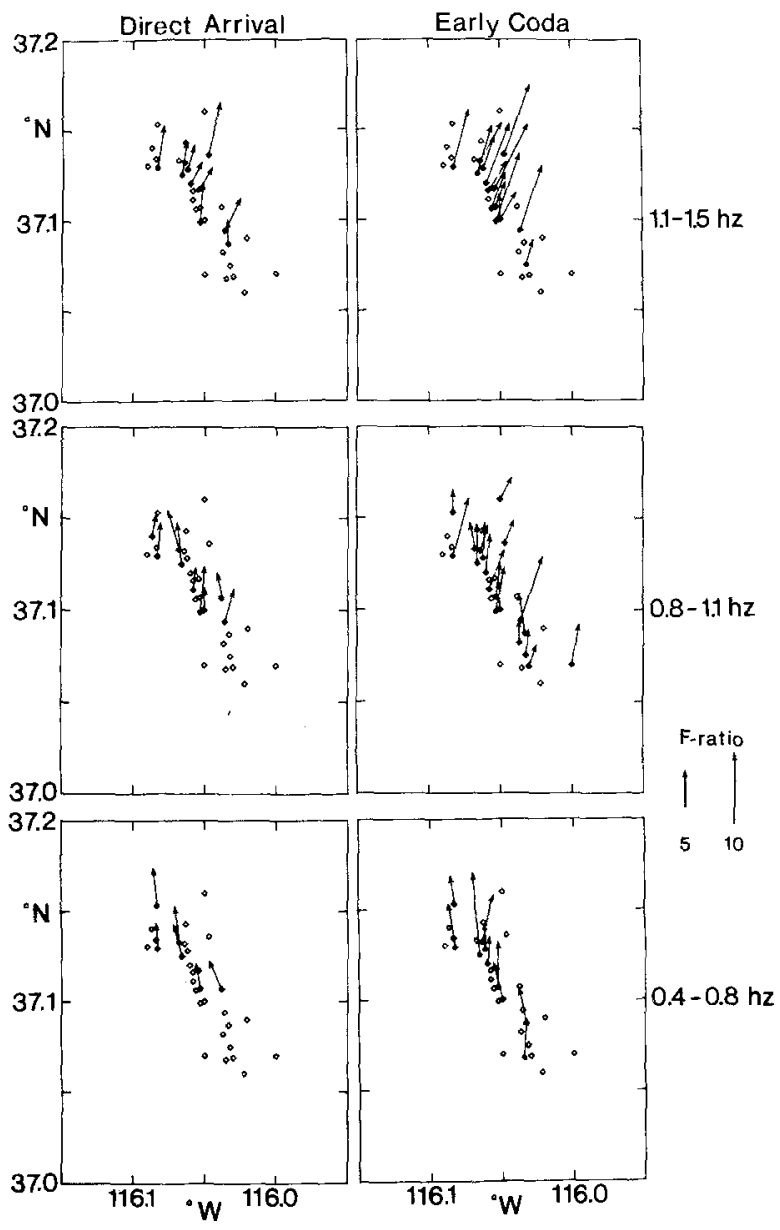

Figure 8

Map of Yucca Flat showing the $F$-ratios and azimuths of the negative lobes of $\sin 2 \theta$ regressions for individual events in the low-frequency, mid-frequency and high-frequency bands. The first column shows results for $\log \left(\mathrm{RMS}^{0-5}\right)$, the second shows $\log \left(\mathrm{RMS}^{5-15}\right)$. The length of the arrow is proportional to the $F$-ratio. Arrows for events with an $F$-ratio lower than 3 are not shown. 
In order to further explore the frequency dependence of the focussing and/or scattering effects, sine curves were regressed through $\log \left(\mathrm{RMS}^{0-5}\right), \log \left(\mathrm{RMS}^{5-15}\right)$ and $\log \left(\mathrm{RMS}^{0-5} / \mathrm{RMS}^{5-15}\right)$ measures of individual events from both test sites in all four frequency bands. The $F$-ratios and the directions of the negative lobes of the direct arrival and early coda patterns in the low-frequency, mid-frequency and high-frequency bands for Yucca Flat are shown in Figure 8. As with the broadband results, the regressions of $\log \left(\mathrm{RMS}^{0-5}\right)$ values have systematically smaller $F$-ratios than the $\log \left(\right.$ RMS $\left.^{5-15}\right)$ measurements; however, the amplitudes and azimuths are quite similar for a given frequency band. In addition, there is a systematic clockwise rotation in the long-wavelength patterns with frequency from $2^{\circ}-4^{\circ}$ (azimuth of the negative lobe) in the low-frequency band to $11^{\circ}-13^{\circ}$ in the mid-frequency band to $17^{\circ}-20^{\circ}$ in the high-frequency band.

The $F$-ratios and azimuths of individual event patterns in the inverse complexity for all four frequency bands are shown in Figure 9 for both test sites. There were too few significant sine curves to deduce any frequency dependence in azimuthal patterns of complexity for Yucca Flat, but a spatial dependence does appear in that those few sine curves that are significant tend to be for events at the southern end of the test
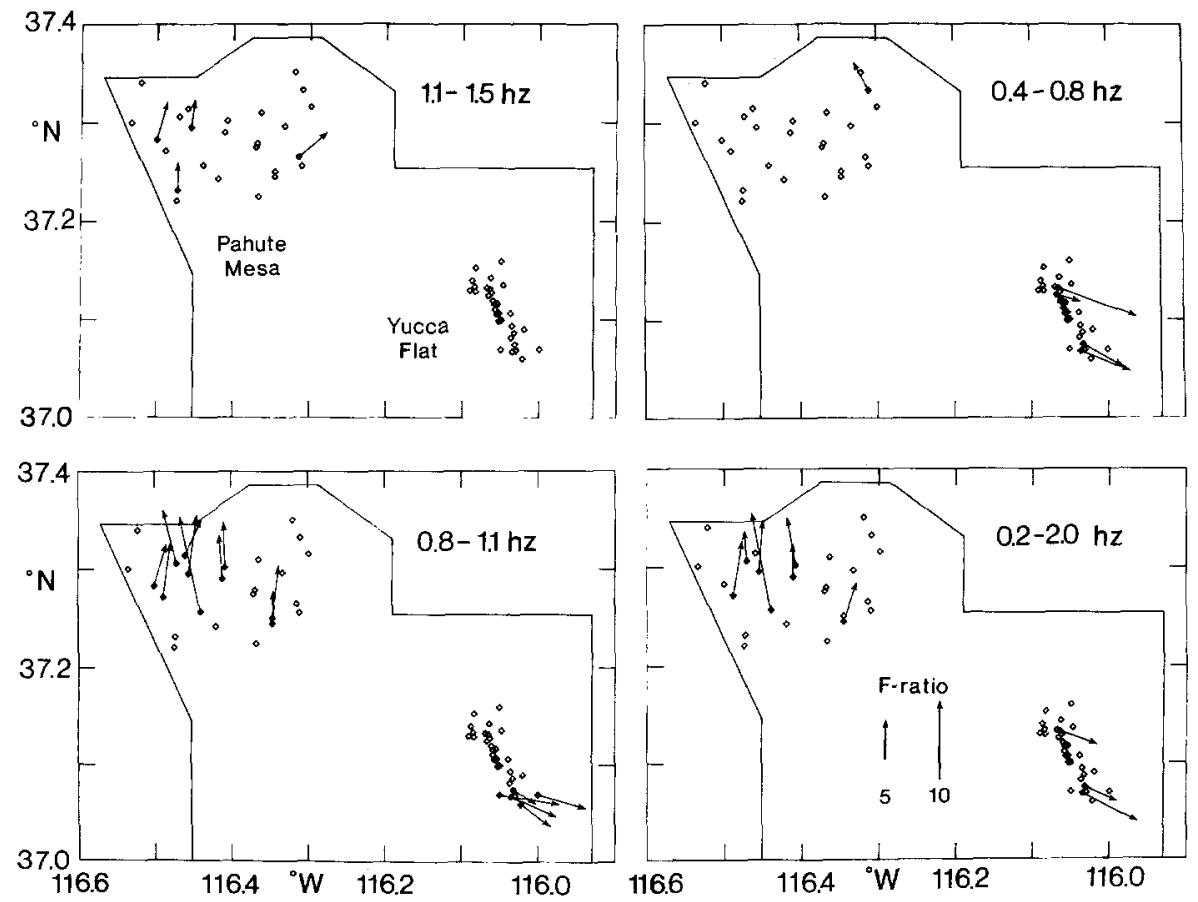

Figure 9

Map of the Nevada Test Site showing the $F$-ratios and azimuths of the negative lobes of $\sin 2 \theta$ regressions through $\log \left(\mathrm{RMS}^{0-5} / \mathrm{RMS}^{5-15}\right)$ (inverse complexity) for individual events in the broadband, lowfrequency, mid-frequency and high-frequency ranges. 
array. On the other hand, Pahute Mesa, events clearly exhibit a frequency dependence, as there are more events with coherent patterns in the mid-frequency band than in any other band. Thus, it appears that it is the signal in this passband that produces the significant azimuthal patterns for Pahute Mesa complexity observed by LAY and WeLC (1987) for events in the middle of the mesa. Furthermore, almost all of the events with significant patterns in this passband are in the central part of the mesa, supporting the hypothesis that frequency dependence of focussing/defocussing or scattering of the direct arrival plays a role in producing these patterns. Because the large events tend to be located in the center of the mesa, frequency-dependent focussing may also help to explain the positive correlation of complexity with magnitude in the mid-frequency band, rather than simply $p P$ variations.

\section{Discussion}

One of the most difficult observations to explain from this paper and LAY (1987a) is the dependence of complexity on magnitude. All sites studied so far have exhibited enriched long period $(0.4-0.8 \mathrm{~Hz})$ energy in the coda, relative to the direct arrival for smaller events. At Pahute Mesa, this effect could in fact be a dependence on depth of burial. LAY (1987a) suggests that a negative correlation of long period complexity with depth could ensue from increased Rayleigh-to- $P$ scattering for the shallower events. However, the depth dependence is slightly weaker than the magnitude dependence at Pahute Mesa, and is quite a bit weaker than the magnitude dependence at Yucca Flat, suggesting that some variable more directly related to source size controls long-period complexity. Such an effect would seem to be intrinsically nonlinear, and as yet there does not seem to be an adequate explanation for this phenomenon. One possibility is that the cavity size influences the excitation of near-field Rayleigh waves, which scatter into the teleseismic wavefield, or that asymmetry exists in the spectrum of energy radiated horizontally relative to that radiated vertically. Numerical simulations are needed to explore these possibilities.

The spatial variations in complexity found for both Pahute Mesa and Yucca Flat strongly suggest that information about the source region structure is contained in the teleseismic $P$ wave coda. These variations are slightly dependent on the frequency band, being particularly coherent in the mid-frequency band at both test sites. The spatial dependence of event complexity at Pahute Mesa is difficult to separate from the size dependence since the largest events are located near the center of the mesa. However, the strong azimuthal patterns of complexity and $\log \left(\mathrm{RMS}^{0-5}\right)$ for events near the center of the mesa suggest that defocussing of the direct arrivals is part of the cause of the enhanced complexity of the coda in the mid-frequency band. The spatial dependence in the mid-frequency band for Yucca Flat is slightly easier to interpret since event complexity in this band is not complicated by depth or magnitude dependence. Clearly, some near-source factor affects complexity. Possible 
candidates are the thickness of the Tertiary tuffs, which may give rise to larger Rayleigh waves in the center of the basin (Figure 6), or the basin shape itself, which may defocus the direct arrivals to the north for events in the center of the basin. However, it is difficult to determine what effect these two factors would have without sophisticated finite-difference modeling (e.g., STEAD and Helmberger, 1986).

While the event average complexity results point to near-source information in the ratio of the coda to the direct arrival, the azimuthal patterns of the early coda for Yucca Flat emphasize the sizable contribution of a deep mantle effect. The most surprising result is the high significance of the long wavelength component for the coda relative to the direct arrival. This behavior contrasts with that for Pahute Mesa, where the direct arrivals seem to be more strongly defocussed to the north by relatively shallow structure than the coda. The increased scatter in the Yucca Flat direct signals suggests that the direct arrivals from the individual events pass through very shallow structure that has little influence on the scattered phases making up the coda (Figure 10). Thus, the coda comprises arrivals that leave the source region with a

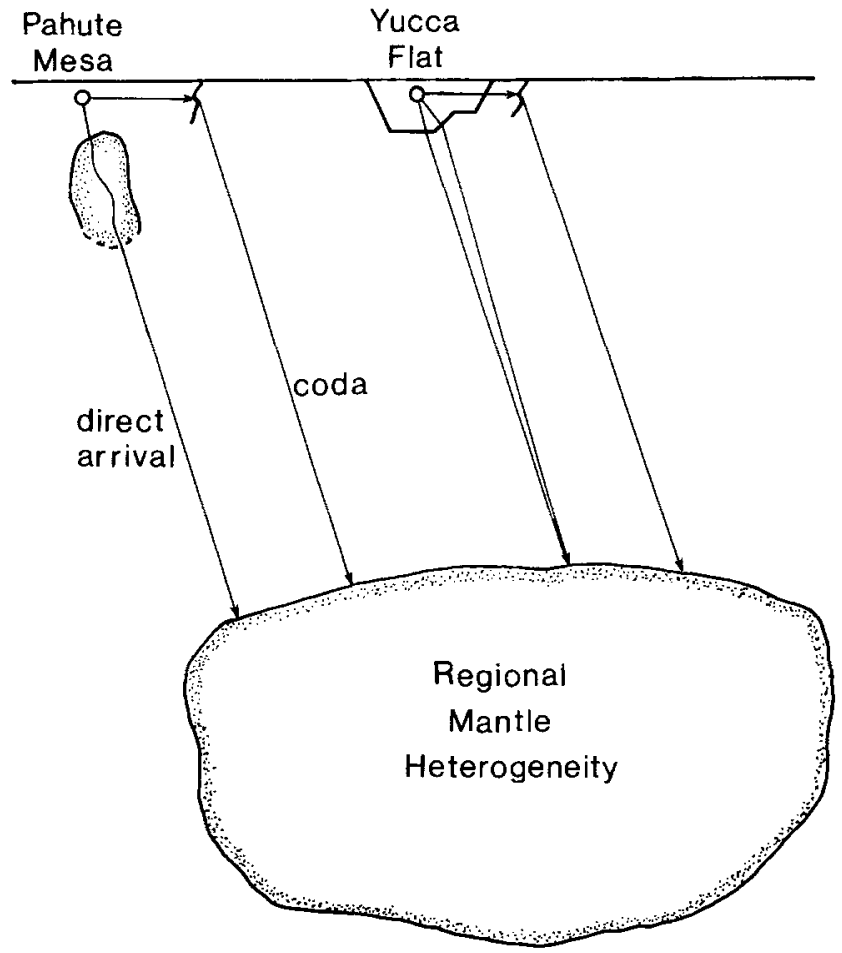

Figure 10

Schematic diagram showing the effects of near-source and deep mantle heterogeneity at the Nevada Test Site. Direct arrivals from Pahute Mesa are defocussed by a high-velocity structure that does not affect the scattered phase. Direct arrivals from Yucca Flat are complicated by triplications and caustics resulting from the basin structure. All of the arrivals are then affected similarly by a deep, regional mantle heterogeneity, which imparts a common azimuthal pattern to direct arrivals and coda from both test sites. 
smaller amplitude variability than the direct downgoing energy. Then the entire signal encounters the deep mantle heterogeneity inferred by LYNNES and LAY (1988), which imparts a common azimuthal pattern. The direct arrivals have the same superimposed variation, but the significance of the long wavelength component is reduced by the additional scatter from very near-source or near-receiver heterogeneity.

The presence of strong azimuthal patterns in the early $P$ coda for Yucca Flat events raises the question of whether the early $P$ coda is a more precise estimator of source size than the direct arrival for Yucca Flat events. To answer this question, the event standard deviations were averaged for the three measures $m_{b}^{a b}, \log \left(\mathrm{RMS}^{0-5}\right)$, and $\log \left(\mathrm{RMS}^{5-15}\right)$ : the average standard deviations are $0.14 \pm .02$ for $m_{b}^{a b}, 0.15 \pm .02$ for $\log \left(\mathrm{RMS}^{0-5}\right)$, and $0.18 \pm .02$ for $\log \left(\mathrm{RMS}^{5-15}\right)$. Thus, the early $P$ coda actually has somewhat higher variance than the direct arrival for Yucca Flat events. While this difference may be partially due to the increased effect of noise, most of the variance in the early coda would seem to result from the long wavelength component produced by deep mantle heterogeneity.

Although the network-averaged coda measurements from Yucca Flat events are less precise than the $m_{b}$ measurements, BAUMGARDT (1985) found that the standard deviation of $P$ coda across NORSAR for Semipalitinsk events was even less than that of the noise across the array. This suggests that array-averaged coda measurements are more precise than network-averaged $P$ or $P$ coda. Indeed, azimuthal patterns in the coda such as those from NTS would produce a large degree of scatter in networkaveraged measurements, but very little additional scatter at a single array, leading to a comparable or higher precision at the latter.

Even more important than the precision of the different measures, however, is their accuracy. Clearly, measurements of the coda from NTS at a single station or array have a high probability of falling on one of the lobes of the azimuthal pattern from NTS. (NORSAR, for instance, occurs near the minimum of the Pahute Mesa and Yucca Flat azimuthal amplitude patterns.) Consequently, single arrays may record coda magnitudes with very high precision by averaging out the near-receiver effects, but cannot average out effects imparted by mantle heterogeneity near the source region, resulting in an absolute bias.

\section{Conclusions}

Data-intensive analysis of teleseismic $P$ wave signals has been used to isolate near-source contributions to the early coda from NTS events. The $0.4-0.8 \mathrm{~Hz}$ frequency band has a strong negative correlation between coda complexity and magnitude at both the Pahute Mesa and Yucca Flat test sites, with smaller events having higher coda levels. Effects related to depth of burial alone do not seem sufficient to explain this correlation, since the correlation of complexity with depth for Yucca Flat is fairly low. 
Coherent spatial variations can also be seen in event-averaged coda complexity for both test sites. These variations are strongest in the $0.8-1.1 \mathrm{~Hz}$ frequency band, and the patterns vary with frequency for Yucca Flat events. Thus, some frequency dependence of focussing/defocussing or scattering is indicated. The Pahute Mesa events in the center of the test array generally have larger coda levels relative to the direct arrivals. This appears to be at least partially due to defocussing of the direct arrivals by high velocities to the northeast under the mesa. The mid-frequency event average complexity for Yucca Flat is large in the northern part of the array, above the western axis of the Yucca Flat basin, and small in the northwest, above the east flank of a basement horst. These strong spatial variations imply a significant nearsource contribution to the coda, which could be exploited in an inversion for scatterers similar to that of LAY (1987b) for Pahute Mesa.

Strong, slowly varying azimuthal amplitude patterns in both the direct arrival and coda are apparent for both test sites. While the azimuthal pattern is stronger in the direct arrivals than in the early coda for Pahute Mesa events due to crustal and shallow mantle scattering or defocussing, the reverse is true for Yucca Flat, possibly due to very near-source heterogeneity such as basement structure. The common component of the amplitude patterns in the direct arrivals and early coda for the two test sites appears to be due to focussing and defocussing by deep mantle heterogeneity. Such heterogeneity must be considered as a possible source of bias when using coda for size estimation.

\section{Acknowledgements}

Judi Sheridan and Martha Ballard digitized many of the seismograms used in this study. This paper benefited much from comments of two anonymous reviewers. This research was supported by the Sloan Foundation, a Shell Faculty Career Initiation Grant, and the Defense Advanced Research Projects Agency, and was monitored by the Air Force Geophysics Laboratory under Contract F19628-87-K-0010.

\section{REFERENCES}

AKI, K. (1982), Scattering and attenuation, Bull. Seism. Soc. Am. 72, S319-S330.

BACHE, T. (1982), Estimating the yield of underground explosions, Bull. Seism. Soc. Am. 72, S131-S168.

BAumgarDT, D. R. (1985), Comparative analysis of teleseismic $P$ coda and Lg waves from underground nuclear explosions in Eurasia, Bull. Seism. Soc. Am. 75, 1413-1433.

BouCHER, G. (1973), Local seismic phenomena in the first three seconds after underground nuclear explosions, J. Geophys. Res. 78, 1348-1360.

BullitT, J. T. and CORMIER, V. F. (1984), The relative performance of $m_{b}$ and alternative measures of elastic energy in estimating source size and explosion yield, Bull. Seism. Soc. Am. 74, 1863-1882.

Cormier, V. F. (1987), Focusing and defocusing of teleseismic $P$ waves by known 3-d structure beneath Pahute Mesa, Nevada Test Site, Bull. Seism. Soc. Am. 77, 1688-1703. 
DAINTY, A. M. (1985), Coda observed at NORSAR and NORESS, Final Technical Report, AFGL-TR85-0199, Hanscom AFB, MA, 73 p.

DOUGLAS, A. (1984), Teleseismic observations of aftershocks immediately following an underground explosion, Geophys. J. Roy. Astr. Soc. 77, 503-515.

FERGUSON, J. F. (1982), Geophysical investigations of Yucca Flat, Nevada, in Final Technical Report to the AFOSR, Contract no. F49620-81-C-0010.

GuPTA, I. N. and BlANDFORD, R. R. (1987), A study of $P$ waves from NTS explosions-near-source information from teleseismic observations? Bull. Seism. Soc. Am. 77, 1041-1056.

Gupta, I. N., Blandford, R. R., WAGner, R. A., Burnetti, J. A., and McElfresh, T. W. (1985), Use of $P$ coda for determination of yield of nuclear explosions, Geophys. J. Roy. Astr. Soc. 83, $541-553$.

LAY, T. (1985), Estimating explosion yield by analytical waveform comparison, Geophys. J. Roy. Astr. Soc. $82,1-31$.

LAY, T. (1987a), Analysis of near-source contributions to early $P$ wave coda for underground explosions: 2. Frequency dependence, Bull. Seism. Soc. Am. 77, 1252-1273.

LAY, T. (1987b), Analysis of near-source contributions to early $P$ wave coda for underground explosions: 3. Inversion for isotropic scatterers, Bull. Seism. Soc. Am. 77, 1767-1783.

LAy, T., Burdick, L. J., and Helmberger, D. V. (1984), Estimating the yields of the Amchitka tests by waveform intercorrelation, Geophys. J. Roy. Astr. Soc. 78, 181-208.

LAY, T. and WELC, J. (1987), Analysis of near-source contributions to early $P$ wave coda for underground explosions: 1. Waveform complexity, Bull. Seism. Soc. Am. 77, 1017-1040.

LYNNES, C. S. and LAY, T. (1988), Analysis of amplitude and travel time anomalies for short-period $P$ waves from NTS explosions, Geophys. J. 92, 431-443.

MCLaughlin, K. F. and Anderson, L. M. (1985), $P$ wave dispersion due to scattering and the effects on attenuation and magnitude determination, in The Vela Program (ed. A. U. Kerr) pp. 433-422.

Minster, J. B., SAvino, J. M., Rodi, W. L., Jordan, T. H. and MAsso, J. F. (1981), Three-dimensional velocity structure of the crust and upper mantle beneath the Nevada test site, Final Technical Report SSS-R-81-5318, Science, Systems and Software, La Jolla, California.

Stead, R. J. and Helmberger, D. V. (1986), Progress in modeling strong motions of NTS (abstract), EOS, Transactions of the American Geophysical Union 67, 1093.

TAYLOR, S. R. (1983), Three-dimensional crust and upper mantle structure at the Nevada Test Site, J. Geophys. Res. 88, 2220-2232.

Received March 15, 1987, revised August 11, 1987, accepted August 15, 1987) 